\title{
PRODUÇÃO MAIS LIMPA DA CONSTRUÇÃO CIVIL: O CASO DA ALVENARIA DE BLOCO CERÂMICO E BLOCO DE CONCRETO
}

\author{
Milena Mota Costa $1^{1}$, Cristiano José Monteiro Pinto Junior $2^{2}$; Diego Lima Medeiros \\ $3^{2}$ \\ ${ }^{1}$ Universidade Federal da Bahia; Salvador/Bahia; milena1244@hotmail.com \\ ${ }^{2}$ Universidade Federal da Bahia; Salvador/Bahia.
}

Resumo: A indústria da construção civil é uma das maiores usuárias de recursos naturais e geradoras de resíduos sólidos. Por conta disso, é uma causadora de impactos ambientais, seja por descarte inadequado, mau gerenciamento dos resíduos ou até mesmo pela falta de qualificação técnica para redução das perdas e aproveitamento dos materiais após o seu uso (reciclagem). Nesse sentido, o presente trabalho analisou a viabilidade técnica, ambiental e econômica de procedimentos da engenharia civil referente a alvenaria. Foi sugerido dois processos de alvenaria (uso de bloco cerâmico e bloco de concreto) que atendem aos padrões normativos de aplicação. A alvenaria se apresenta como uma das grandes geradoras de resíduos de obra, portanto a produção mais limpa maximiza a ecoeficiência do canteiro de obra.

Palavras-Chave: Alvenaria; Produção mais limpa; Bloco cerâmico; Bloco de concreto; Resíduo de obra.

\section{CLEANER CONSTRUCTION PRODUCTION: CERAMIC BLOCK AND CONCRETE BLOCK}

Abstract: The construction industry is one of the largest users of natural resources and solid waste generators. Because of this, it is a cause of environmental impacts, either due to improper disposal, poor waste management or even the lack of technical qualification to reduce losses and use of materials after their use (recycling). In this sense, the present work analyzed the technical, environmental and economic feasibility of civil engineering procedures related to masonry. It has been suggested two masonry processes (use of ceramic block and concrete block) that meet the normative application standards. Masonry is one of the major generators of construction waste, so cleaner production maximizes construction site eco-efficiency.

Keywords: Masonry; Cleaner production; Ceramic block; Concrete block; Work waste. 


\section{INTRODUÇÃO}

De acordo com EVANGELISTA (i.e. [1]), o setor da construção civil apresenta-se como um dos setores mais críticos no que diz respeito aos impactos ambientais, pois é responsável por cerca de $50 \%$ do $\mathrm{CO}_{2}$ lançado na atmosfera e por quase metade da quantidade dos resíduos sólidos gerados no mundo. Esta indústria promove uma contribuição de cerca de um décimo do total do Produto Interno Bruto (PIB) global e é responsável por 7\% dos empregos gerados no planeta (i.e. [2]). Em contra partida, este mesmo setor é responsável por cerca de $40 \%$ da degradação dos recursos naturais (i.e. [3]).

O aumento demográfico e o uso demasiado dos recursos naturais, torna mais comum a escassez de recursos e o aumento dos preços, assim como a sobrecarga dos aterros sanitários. Portanto, é incontestável que medidas revolucionárias de sustentabilidade devem ser adotadas. O modelo da economia circular na construção civil é fundamentado na minimização de resíduos ao longo de todo o ciclo da construção. A economia circular se opõe a economia linear (extrair, transformar e descartar) considerando o retorno dos materiais à linha de produção de forma eficiente. Dessa forma, a economia circular apresenta um alto potencial de resolver os desafios ambientais do setor da construção civil, além de propor oportunidades de mercado e crescimento econômico com novas tecnologias e modelos de negócio (i.e. [4]).

A construção civil é responsável por parte considerável dos resíduos gerados nas cidades. Contudo, diante da complexidade que envolve a mudança, necessitase de ações em várias frentes de maneira combinada e simultânea. Desta forma, é indispensável a gerência eficaz dos processos da construção civil durante todo ciclo construtivo, ou seja, o planejamento, concepção, construção propriamente dita e demolição. A construção de alvenaria com bloco cerâmico é uma etapa muito dispendiosa. Posto isso, e tendo em vista a precariedade de práticas sustentáveis na construção civil e o impacto promovido por essa indústria, o estudo em questão analisou um dos processos da cadeia produtiva da construção civil: a alvenaria de bloco cerâmico. A proposta do trabalho foi demonstrar a viabilidade técnica e financeira de técnicas mais limpas da construção de alvenaria de bloco cerâmico. Apesar destas técnicas estarem disponíveis no mercado construtivo brasileiro, elas são pouco praticadas.

\section{MÉTODOLOGIA}

Foram analisados os aspectos técnicos, financeiros e ambientais de tecnologias disponíveis no mercado para a construção de alvenaria com bloco cerâmico. O estudo analisou três métodos construtivos: uso de assentador de argamassa, construção modular e uso de agregado reciclado. A Tabela 1 apresenta as principais perdas da construção de alvenaria com bloco cerâmico. 
\begin{tabular}{l|l} 
CIRCULAR ECONOMY & ECONOMIA CIRCULAR
\end{tabular}

Tabela 1. Insumos da alvenaria de bloco cerâmico e destino das suas perdas na obra

\begin{tabular}{|c|c|c|}
\hline № & Insumo & Destino da perda na obra \\
\hline $\mathbf{1}$ & Água & Absorção pelo solo e evaporação \\
\hline $\mathbf{2}$ & Bloco cerâmico & Caçamba estacionária \\
\hline $\mathbf{3}$ & Argamassa & Caçamba estacionária \\
\hline
\end{tabular}

O custo do assentamento do bloco foi estimado a partir da Eq. 1 para o Cenário base e Cenário 1 .

Custo do assentamento de bloco = argamassa + mão de obra (1)

Foram usados dados da tabela SINAPI (i.e. [5]) de insumos e composições. O custo de produção para $1 \mathrm{~m}^{2}$ de alvenaria, levando em consideração apenas a argamassa de assentamento e a mão de obra, do Cenário base foi $R \$ 4,48$ da argamassa de assentamento de traço 1:2:8 e $R \$ 14,50$ da mão de obra. A seguir são apresentados dois estudos de caso analisados para reduzir as perdas associadas a construção da alvenaria de bloco cerâmico.

\subsection{Cenário 1 - Assentador de argamassa}

A técnica utilizada comumente para alvenaria com bloco cerâmico é a convencional, um método arcaico e artesanal. Esta técnica consiste, basicamente, em utilizar uma colher de pedreiro para assentar a argamassa nas superfícies do bloco, assentando um ao outro de modo a tornar a alvenaria coesa e firme. Posto isso, foi proposta a técnica que utiliza o assentador de argamassa para realizar a mesma tarefa.

Trata-se de uma alternativa, conhecida no mercado, contudo não comum em obras, que se propõem a substituir o método convencional. Deste modo, a aplicação direta da argamassa com a colher de pedreiro pode ser substituída pela utilização de um equipamento para assentar a argamassa na superfície do bloco (Figura 1). 0 assentador de argamassa, além de reduzir a quantidade de material utilizado, chegando a uma redução de até $80 \%$ do aglomerado, como garante os fabricantes, propicia a redução do tempo para realização do serviço. Além disso, a quantidade de argamassa aplicada nos tijolos é uniforme e essa aplicação é feita de uma só vez em toda a fileira de blocos.

Figura 1. Utilização de um assentador de argamassa

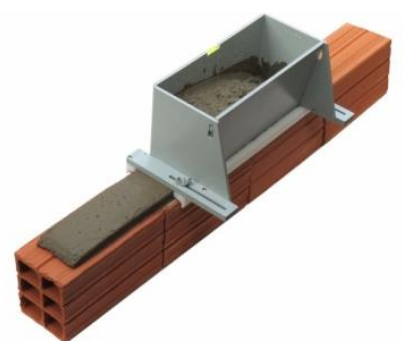


Neste sentido, o aumento da produtividade representa uma economia de tempo correspondente a $50 \%$ em relação ao método convencional. Ou seja, trata-se de uma técnica que dinamiza um dos processos de execução dos serviços e diminui o montante de material consumido, aumentando a produtividade do trabalho e eliminando o desperdício de materiais. Além disso, o assentador de argamassa não exige muita repetição e esforço físico excessivo das pessoas que estão executando o serviço quando comparado ao método convencional. Levando em consideração apenas a argamassa de assentamento e a mão de obra, o custo de produção para 1 $\mathrm{m}^{2}$ de alvenaria no Cenário 1 foi $\mathrm{R} \$ 0,90$ da argamassa de assentamento de traço 1:2:8 e $\mathrm{R} \$ 7,25$ da mão de obra.

\subsection{Cenário 2 - Construção modular}

A fim de maximizar não somente o fator econômico, mas também a redução da perda do material utilizado, a utilização de blocos de concreto apresenta-se como uma solução atrativa em relação a vedação convencional com blocos cerâmicos. Levando em consideração a perda excessiva dos blocos cerâmicos do processo de alvenaria durante a obra, os blocos pré-dimensionados possuem um encaixe perfeito que reduz a necessidade de recortes e utilização da argamassa. O bloco de concreto (Figura 2) também traz consigo uma vantagem inerente as instalações elétricas e hidráulicas, já que são dimensionados e estabelecidos de acordo com os padrões a serem utilizados.

Figura 2. Blocos de concreto

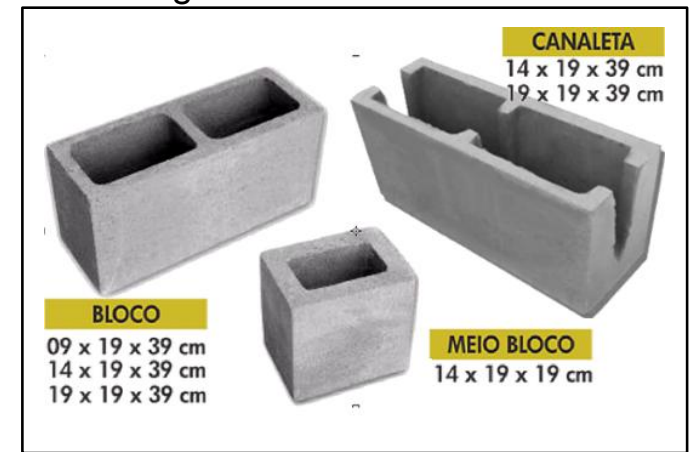

A Votorantim especifica que os blocos de concreto também apresentam maior resistência em relação ao cerâmico, apresentando uma resistência a compressão de 4 a 30Mpa, enquanto que o cerâmico gira em torno de 3 a 6Mpa. Com isso, o bloco de concreto torna-se mais atrativo por dar um "upgrade" no fator resistência da obra, além de proporcionar um maior isolamento acústico.

O aspecto mecânico da execução da alvenaria com bloco de concreto exige menor esforço proveniente da mão de obra comparado ao método convencional, o que gera de $30 \%$ a $50 \%$ de aumento da eficiência no tempo de realização da alvenaria. $\mathrm{O}$ bloco de concreto também reduz o consumo de argamassa em suas juntas de $10 \%$ a $20 \%$ por ser mais plano que o bloco convencional, e também 
economiza, posteriormente, na realização do revestimento. O bloco de concreto pode atuar no fator estrutural da construção por ser resistente, porém apresenta dificuldade de manutenção e inserção de novas instalações.

\section{RESULTADOS E DISCUSSÃO}

A técnica convencional de assentamento de argamassa (Cenário base) apresentou um custo de $\mathrm{R} \$ 18,98$ por $\mathrm{m}^{2}$ de alvenaria assentada, enquanto o uso do assentador de argamassa (Cenário 1) apresentou um custo de $\mathrm{R} \$ 8,15$ por $\mathrm{m}^{2}$ (Figura 3).

Figura 3. Diagrama do custo do cenário base e do cenário 1

Mão de obra

Argamassa de assentamento de traço 1:2:8

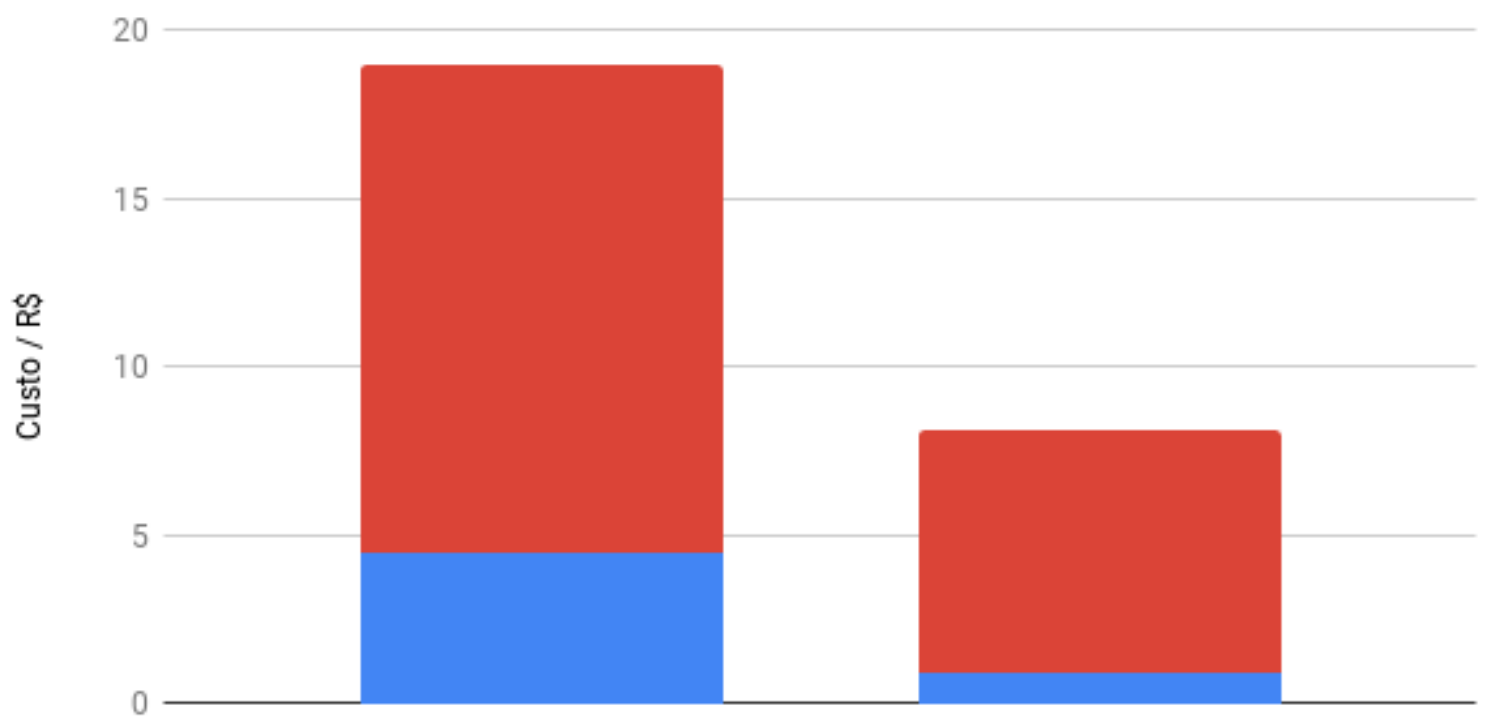

Cenário base

Cenário 1

A utilização do assentador de argamassa é a técnica que propõem uma redução considerável do consumo, aumentando a produtividade de execução do serviço. O uso do assentador de argamassa, que custa $\mathrm{R} \$ 280,00$, apresenta uma economia de $57 \%$ do valor gasto para a realização do mesmo serviço. Portanto, o custo do equipamento retorna a empresa a partir da execução de $26 \mathrm{~m}^{2}$ de alvenaria construída. O assentador de argamassa contribui também na questão ambiental, uma vez que estaria minimizando os impactos que são gerados com a produção e destinação dos materiais perdidos na obra. Apesar disso, vale ressaltar que é necessário um maior investimento em capacitação técnica dos funcionários para que os mesmos se adaptem e apliquem o novo procedimento com êxito.

Com os benefícios financeiros que essa medida traz para o empreendimento, o impacto ambiental proporcionado pela utilização de água na alvenaria também é minimizado. Diante da crescente demanda por esse insumo e do seu mau uso, 
torna-se cada vez mais intensa a preocupação com a crise hídrica. Dessa forma, a economia de água na obra contribui com a preservação desse recurso natural que tem se tornado mais escasso.

$\mathrm{Na}$ construção civil, umas das grandes barreiras a serem rompidas é a utilização de materiais alternativos à alvenaria de bloco cerâmico. De acordo com a Votorantim, uma solução para essa problemática é a construção modular, que além de possibilitar uma redução do consumo de material e geração de resíduo, possibilita um aumento na produtividade, economia de energia e financeira, podendo utilizar cerca de 12,5 peças por $\mathrm{m}^{2}$, além de beneficiar o aspecto estrutural da obra, enquanto que o cerâmico necessita de 23 peças por $\mathrm{m}^{2}$.

Apesar de, unitariamente, ser mais oneroso que o bloco cerâmico, o bloco de concreto tende a apresentar maior resistência evitando perdas excessivas no transporte e manuseio, e quando associado ao dimensionamento previsto em projeto, sua utilização evita recortes para passagem de tubulações e eletrodutos, eliminando as adequações. Através da utilização da tabela SINAPI (i.e. [5]), o orçamento previsto para a construção da alvenaria por $\mathrm{m}^{2}$, levando em consideração as adequações necessárias, apresentou valores para blocos de concreto de $\mathrm{R} \$ 66,27$ enquanto que para alvenaria com blocos cerâmicos apresentou um valor de $\mathrm{R} \$ 71,87$, fazendo com que o bloco de concreto, também, se sobressaísse no fator econômico.

Um paradigma a ser rompido na construção civil é a qualificação da mão de obra. Funcionários desqualificados e desmotivados são um dos principais problemas para aumentar a ecoeficiência do canteiro de obra. $O$ despreparo da mão de obra gera perdas de materiais, baixa produtividade, mal-uso dos equipamentos e baixa competitividade com outras empresas do mercado. As técnicas adequadas para executar as rotinas diariamente e reduzir os custos com materiais e produtos desnecessários demandam a capacitação dos colaboradores.

Os cenários analisados mostram que a inovação é essencial, principalmente em períodos de economia com baixas taxas de crescimento, para otimizar o uso de materiais, mão de obra e tempo de execução da obra. As propostas de aumento da eficiência do uso de insumos e mão de obra (Cenário 1 e Cenário 2) apresentaram vantagens técnicas, ambientais e econômicas (Cenário 1), que aumentam a sua atratividade no mercado. Ademais, o uso de materiais, técnicas inovadoras e qualificação da mão de obra devem ser combinadas com o gerenciamento efetivo.

\section{CONCLUSÃO (ARIAL 12)}

Neste trabalho foram analisados dois cenários alternativos de construção de alvenaria, o primeiro considerou a implementação do assentador de argamassa em alvenaria de bloco cerâmico, e o segundo se referiu ao conceito de construção modular com bloco de concreto. Nota-se que ambas as alternativas estão disponíveis no mercado e são praticadas em vários lugares do mundo, todavia, essas práticas são pouco comuns no Brasil. Reduzindo a extensão geográfica para o município de Salvador, é insignificante o número de obras que aplicam essas 
propostas. Uma fala constante entre os construtores é "faço assim a várias décadas e sempre deu certo, porque fazer diferente agora?". Esse tipo de mentalidade impede a inserção de novas técnicas e conceitos no mercado, mesmo que sejam consideravelmente mais eficientes que aquelas empregadas. A efeito disso, nota-se que a forma predominante de construir não é aquela mais eficiente e sustentável, principalmente quando se considera a durabilidade do ambiente construído.

As propostas analisadas incluem técnicas aplicáveis a diversas obras para minimizar o desperdício de material e tempo de execução da construção. Sendo a aplicação conjunta das proposições de assentador de argamassa e construção modular pode gerar uma economia de $40 \%$ a $60 \%$ da demanda de argamassa, bem como a redução do desperdício de água. Esses métodos também demonstram uma redução na geração de resíduos de quebras para adequação da peça e transpasse de tubulações elétricas ou hidráulicas. Portanto, foi percebido que o estudo prévio e a organização do canteiro de obra, associado sempre aos cronogramas de execução, podem aumentar a ecoeficiência do processo construtivo, especialmente no processo de alvenaria de uma construção civil.

\section{Agradecimentos}

Aos professores da disciplina Ciências do Ambiente da Universidade Federal da Bahia (UFBA) que iniciaram a discussão para elaboração desse trabalho.

\section{REFERÊNCIAS}

${ }^{1}$ EVANGELISTA, P. P. A.; COSTA, D. B.; ZANTA, V. M. Alternativa sustentável para destinação de resíduos de construção classe A: sistemática para reciclagem em canteiros de obras. Disponível em: <http://www.scielo.br/pdf/ac/v10n3/a02.pdf>. Acesso em: 15 de jul. de 2019.

${ }^{2}$ AZEVEDO, Juliana Laboissière. A economia circular aplicada no Brasil: uma análise a partir dos instrumentos legais existentes para a logística reversa. Brasil: CONGRESSO NACIONAL DE EXCELÊNCIA EM GESTÃO, 2015. Disponível em: <http://www.inovarse.org/node/3815>. Acesso em: 10 de jul. 2019.

\footnotetext{
${ }^{3}$ ESA, M. R.; HALOG, A.; RIGAMONTI, L. Developing strategies for managing construction and demolition wastes in Malaysia based on the concept of circular economy. Disponível em:<https://www.academia.edu/25900851/Developing_strategies_for_managing_con struction_and_demolition_wastes_in_Malaysia_based_on_the_concept_of_circular_ economy . Acesso em: 15 de jul. 2019.
} 
${ }^{4}$ MORATÓ, Jordi et al. Situación y evolución de la economía circular en España. Espanha: COTEC, 2017. Disponível em: < http://cotec.es/media/informe-CotecISBN1.pdf>. Acesso em: 13 de jul. 2019.

${ }^{5}$ SINAPI, Sistema Nacional de Pesquisa de Custos e Índices da Construção Civil, junho de 2019.

6UNAMA. ALVENARIA. Belém 2009. Disponível em: <https://www.ebah.com.br/content/ABAAAAiOIAF/alvenaria-vedacao>. Acesso em: 21 de jul. 2019.

${ }^{7}$ SANTOS, Everton de Brito. ESTUDO COMPARATIVO DE VIABILIDADE ENTRE ALVENARIA DE BLOCOS CERÂMICOS E PAREDES DE CONCRETO MOLDADAS NO LOCAL COM FÔRMAS METÁLICAS EM HABITAÇÕES POPULARES. Campo Mourão 2013. Disponível em: $<$ http://repositorio.roca.utfpr.edu.br/jspui/bitstream/-

1/1869/1/CM_COECl_2013_1_04.pdf>. Acesso em: 19 de jul. 2019.

${ }^{8}$ VOTORANTIM. Blocos de concreto: principais vantagens e características. Publicado em: 18/08/2017. Disponível em: <https://www.mapadaobra.com.br/capacitacao/bloco-de-cimento-estrutural-vantagens/>. Acesso em: 17 de jul. de 2019.

${ }^{9}$ SOUZA, D. M. DE et al. Comparative life cycle assessment of ceramic brick, concrete brick and cast-in-place reinforced concrete exterior walls. Journal of Cleaner Production, v. 137, p. 70-82, 2016.

${ }^{10}$ CONAMA, Conselho Nacional do Meio Ambiente. RESOLUÇÃO № 237, DE 19 DE dezembro DE 1997. Brasil, 1997. 